\title{
RAZONES PARA REALIZAR LAS INYECCIONES INTRAVÍTREAS EN EL CONSULTORIO OFTALMOLÓGICO
}

\section{REASONS FOR USING INTRAVITREOUS INJECTIONS IN THE OPHTHALMOLOGIC OFFICE}

\author{
GÓMEZ-ULLA F ${ }^{1}$, BASAURI E²
}

\begin{abstract}
Desde que Ohm (1) publicó hace ya casi un siglo su técnica de inyección intravítrea de aire para tratar el desprendimiento de retina, esta vía de administración se ha ido generalizando progresivamente para tratar otras muchas enfermedades como endoftalmitis, retinitis por citomegalovirus, neovascularización coroidea secundaria a DMAE o a miopía patológica, edema macular secundario a diabetes, a oclusiones venosas, etc., lo que probablemente convierte a esta técnica en el procedimiento más frecuente en la consulta de un retinólogo.
\end{abstract}

En muchas de las reuniones y congresos oftalmológicos sobre tratamientos que requieren la inyección de un fármaco dentro del ojo y especialmente cuando se trata de inyecciones intravítreas, siempre surge la misma discusión sobre en qué lugar -quirófano o consulta- es necesario llevar a cabo el procedimiento.

En el último congreso de la Sociedad Española de Oftalmología celebrado hace ya casi un año en Las Palmas de Gran Canarias y con ocasión de una Mesa Redonda sobre DMAE surgió la pregunta de en qué lugar se debe practicar esta técnica y sorprendentemente la mayoría de los asistentes manifestaron que preferían hacerla en quirófano. Cuando se les preguntó que cuál era la razón, la mayor parte de ellos decían que era para cubrirse ante una eventual reclamación o porque creían que el porcentaje de infecciones era menor. También hicimos esta misma pregunta en el Foro que la Sociedad Panamericana de Retina y Vítreo mantiene en Internet. De los catorce prestigiosos retinólogos que contestaron desde diferentes países, ocho inyectaban en el consultorio y los otros seis manifestaron que lo hacían en el quirófano para evitar problemas legales.

Hemos realizado una revisión bibliográfica sobre endoftalmitis en inyecciones intravítreas y no hemos encontrado ni una sola publicación que se ocupe de la frecuencia de complicaciones dependiendo del lugar en que se realice la inyección. Recientemente Pilli y cols. (2) comunicaron una incidencia de endoftalmitis sospechada de 0,029\% en 10.254 inyecciones intravítreas de anti-VEGF (406 de pegaptanib, 3.501 de bevacizumab y 6.347 de ranibizumab). Todas las inyecciones fueron realizadas en el gabinete del oftalmólogo, no se utilizó paño ocular ni antibióticos previos, pero sí povidona yodada y condiciones habituales de asepsia. $\mathrm{Wu}$ y cols. (3) encontraron una incidencia algo superior de endoftalmitis, $0,16 \%$ en 4,303 inyecciones intravítreas de bevacizumab. Un año antes, Quiroz-Mercado y cols. (4) habían publicado un porcentaje similar de endoftalmitis secundarias a bevacizumab intravítreo practicado en consulta $(0,169 \%$ en 1.765 inyecciones intravítreas). El estudio MARINA (ranibizumab) presenta una incidencia de endoftalmitis por inyección del 0,05\% (5). En caso de que el fármaco inyectado sea triamcinolona estos porcentajes pueden variar entre el 0,6 y el $0,16 \%(6,7)$ o incluso alcanzar el 1,9\% (8). La guía de inyecciones intravítreas publicada en Retina en 2004 (9), tampoco hace ninguna recomendación sobre dónde llevar a cabo el procedimiento y ninguno de los ensayos clínicos con medicación intravítrea ponen como condición realizar las inyecciones en el quirófano.

\footnotetext{
1 Doctor en Medicina. Presidente de la Sociedad Española de Retina y Vítreo. Universidad de Santiago de Compostela. Instituto Tecnológico de Oftalmología (ITO). Santiago de Compostela. La Coruña. España.

E-mail: gomezulla@itogalicia.es

2 Oftalmólogo. Hospital Son Llatzer e Instituto Balear de Oftalmología (IBO). Palma de Mallorca. España.
} 
Las razones que en general son esgrimidas para practicar la inyección en quirófano son pues esencialmente por temor a una demanda, porque es más segura, o para justificarse ante la aparición de una complicación. La primera razón sólo estaría justificada en aquellos países en los que haya una recomendación oficial explícita en el sentido de realizar las inyecciones en la sala de operaciones. La segunda razón no está probada como hemos visto anteriormente, y no parece razonable achacar la infección al aire contaminado de una habitación que muy improbablemente sería el causante de la propagación de las bacterias por un pinchazo con una aguja de 30G (si creyésemos lo contrario también deberíamos realizar una inyección intramuscular en el quirófano). Por último, para que el paciente acepte más fácilmente una complicación, especialmente de la gravedad de una endoftalmitis, difícil de entender por la reacción tan desmesurada secundaria a una «simple inyección», lo que deberemos hacer es explicarle antes claramente la opciones terapéuticas, los riesgos inherentes a la técnica y los relacionados con el propio fármaco, la posibilidad y la frecuencia de la repetición de las inyecciones y además darle por escrito todas estas explicaciones para que las firme, es decir el consentimiento informado.

La inyección intravítrea se ha convertido en un procedimiento habitual y muchas veces repetido en un mismo paciente en enfermedades tales como la DMAE en las que hay que poner una inyección cada cuatro-seis semanas. Indudablemente es mucho más operativo, si no supone un riesgo añadido, realizarla en el propio consultorio y en la misma visita en que se mide la agudeza visual y se hace la exploración oftalmológica y el OCT. En unos tiempos en que hay que «optimizar» los recursos sanitarios y los procedimientos que hacemos, las inyecciones intravítreas suponen un gasto importante en tiempo, recursos humanos y recursos económicos. Esto debemos tenerlo en cuenta siempre que no vaya en detrimento de la calidad del acto médico y de la seguridad del paciente.

La inyección intravítrea es un procedimiento preciso y breve en manos experimentadas. Hay evidencia para afirmar que ciertas medidas profilácticas de asepsia (uso de povidona iodada en párpados, pestañas y conjuntiva, guantes, material y colirios estériles) (9) reducen el riesgo de endoftalmitis. Estas medidas pretenden disminuir la flora bacteriana en el lugar de la inyección y evitar la contaminación de la aguja inyectora, y entre ellas no está incluido el lugar donde llevarla a cabo. Pensamos, que con la evidencia de que disponemos, el consultorio oftalmológico que nos permita realizar el procedimiento aplicando las medidas profilácticas con comodidad, tanto para el paciente como para el oftalmólogo, es un lugar apropiado para la realización de inyecciones intravítreas.

La Sociedad Española de Retina y Vítreo publicará en breve una guía en la que se revisará el protocolo a seguir así como las recomendaciones de la Sociedad entre las que figurara explícitamente que la inyección puede realizarse en el propio consultorio, lo cual podría servir al oftalmólogo como argumento ante una posible demanda siempre que se haya actuado de acuerdo con el protocolo recomendado.

\section{BIBLIOGRAFÍA}

1. Ohm J. Über die Behandlung der Netzhautablösung durch operative Entleerung der Subretinalen Flössigkeit und Einspritzung von Luft in den Glaskörper. Albrecht von Graefes Arch Ophthalmol 1911; 79: 442-450.

2. Pilli S, Kotsolis A, Spaide RF, Slakter J, Freund KB, Sorenson J, et al. Endophthalmitis associated with intravitreal anti-vascular endothelial growth factor therapy injections in an office setting. Am J Ophthalmol 2008; 145: 879-882.

3. Wu L, Martínez-Castellanos MA, Quiroz-Mercado H, Arevalo JF, Berrocal MH, Farah ME, et al. Twelve-month safety of intravitreal injections of bevacizumab (Avastin $(R))$ : results of the Pan-American Collaborative Retina Study Group (PACORES). Graefes Arch Clin Exp Ophthalmol 2008; 246: 81-87.

4. Quiroz-Mercado H, Ustariz-González O, Martinez-Castellanos MA, Covarrubias P, Dominguez, F, Sanchez-Huerta $V$. Our experience after 1765 intravitreal injections of bevacizumab: the importance of being part of a developing story. Semin Ophthalmol 2007; 22: 109-125.

5. Rosenfeld PJ, Brown DM, Heier JS, Boyer DS, Kaiser PK, Chung CY, et al. Ranibizumab for neovascular age-related macular degeneration. N Engl J Med 2006; 355: 14191431

6. Jager RD, Aiello LP, Patel SC, Cunningham ET Jr. Risks of intravitreous injection: a comprehensive review. Retina 2004; 24 : 676-698.

7. Moshfeghi DM, Kaiser PK, Scott IU, Sears JE, Benz M, Sinesterra JP, et al. Acute endophthalmitis following intravitreal triamcinolone acetonide injection. Am J Ophthalmol 2003; 136: 791-796.

8. Jonisch J, Lai JC, Deramo VA, Flug AJ, Fastenberg DM. Increased incidence of sterile endophthalmitis following intravitreal preserved triamcinolone acetonide. Br J Ophthalmol 2008; 92: 1051-1054.

9. Aiello LP, Brucker AJ, Chang S, Cunningham ET Jr, D'Amico DJ, Flynn HW Jr, Grollone LR, et al. Evolving guidelines for intravitreous injections. Retina 2004; 24: S3S19. 